\title{
Adverse prenatal environment and kidney development: implications for programing of adult disease
}

\author{
Emily S Dorey, Marie Pantaleon, Kristy A Weir and Karen M Moritz \\ School of Biomedical Sciences, The University of Queensland, St Lucia, Queensland 4072, Australia \\ Correspondence should be addressed to KM Moritz; Email: k.moritz@uq.edu.au
}

\begin{abstract}
The 'developmental origins of health and disease' hypothesis suggests that many adult-onset diseases can be attributed to altered growth and development during early life. Perturbations during gestation can be detrimental and lead to an increased risk of developing renal, cardiovascular, metabolic, and neurocognitive dysfunction in adulthood. The kidney has emerged as being especially vulnerable to insult at almost any stage of development resulting in a reduction in nephron endowment. In both humans and animal models, a reduction in nephron endowment is strongly associated with an increased risk of hypertension. The focus of this review is twofold: $i)$ to determine the importance of specific periods during development on long-term programing and ii) to examine the effects of maternal perturbations on the developing kidney and how this may program adult-onset disease. Recent evidence has suggested that insults occurring around the time of conception also have the capacity to influence long-term health. Although epigenetic mechanisms are implicated in mediating these outcomes, it is unclear as to how these may impact on kidney development. This presents exciting new challenges and areas for research.
\end{abstract}

Reproduction (2014) 147 R189-R198

\section{Introduction: the developmental origins of health and disease}

The concept of developmental programing of adult-onset disease first evolved through an extensive series of epidemiological studies linking a low birth weight with disease risk in adulthood (Barker 2007). Early investigations, which have since been confirmed in a multitude of studies worldwide, found strong associations between birth weight and risk of developing cardiovascular (Barker \& Osmond 1986) and metabolic diseases (Hales \& Ozanne 2003). Indeed, over the past 10-15 years, the list of diseases that can be 'programed' has been extended to include osteoporosis, kidney disease, lung disease, and some mental illnesses (Gluckman et al. 2008). It is now appreciated that a low birth weight, used as a surrogate marker of poor nutrition in utero, is not essential for programing of adult-onset disease (Moritz et al. 2009), but rather that outcomes are graded across the entire birth weight spectrum (Barker et al. 2012). Independent of growth in utero, early postnatal growth and adult lifestyle factors can modify disease onset and progression (Eriksson et al. 1999). This is proposed to occur through alterations in the normal development of organs and homeostatic mechanisms leading to an increased risk of adult disease (Barker et al. 2012).

A number of animal models have consequently been established to elucidate specific alterations caused by maternal perturbations, which include calorie/protein restriction, exposure to glucocorticoids, and placental insufficiency, that induce a suboptimal in utero environment and program adult-onset disease (Moritz et al. 2008, 2009, O'Sullivan et al. 2012, Gallo et al. 2013). This has allowed interrogation of underlying mechanisms contributing to the development of disease. Whilst these studies have reported that a suboptimal in utero environment can impair the development of many organs including the heart and brain, the kidney has been identified as being particularly vulnerable. This vulnerability may present as a reduction in kidney weight but more importantly also in a reduction in the number of nephrons (Moritz et al. 2008). As all nephrons are formed before birth in the human, this congenital nephron deficit is permanent and has been strongly correlated with an increased risk of hypertension (Keller et al. 2003) and renal disease in later life (Luyckx et al. 2013).

Whilst dietary deficiencies may affect most or all of pregnancy, many perturbations occur for a limited duration during a particular developmental period leading to the concept of 'critical windows' during which development of specific organ systems may be altered. Organogenesis, the period of rapid fetal growth in late gestation, and lactation, have been identified as critical periods of sensitivity. Interestingly, the kidney has been shown to be vulnerable to insult at multiple time 
points throughout gestation as well as postnatally, although, as discussed below, the early stages of renal development appear to be most susceptible. An area now receiving considerable attention is the long-term impact of an adverse periconceptional environment. Even in developed countries where women have ready access to contraceptives, it is estimated that $40-45 \%$ of pregnancies are unplanned (Naimi et al. 2003). The period around the time of conception and early embryonic development represents a time when a woman may unknowingly expose her conceptus to an adverse environment.

The focus of this review is thus twofold: to focus on the importance of different developmental periods as potentially critical determinants of programing and secondly to examine the effects of maternal perturbations on the kidney and how this may program adultonset disease (particularly hypertension). Whilst the periconceptional period represents a highly sensitive period of development, studies to date have mainly explored nutritional insults and potential renal outcomes have yet to be fully explored. The paucity of studies in this area highlights a strong need for continuing research.

\section{Perturbations resulting in developmental programing: the importance of timing}

In the human, poor placental function or maternal under nutrition (including micronutrient deficiencies) are the most likely causes of growth restriction and both are associated with an increased risk of adult disease in offspring including cardiovascular and metabolic diseases (Elmadfa \& Meyer 2012, Barker \& Thornburg 2013). In the last decade, fetal exposure to excess nutrients, often associated with maternal obesity and/or diabetes, has also been identified as a risk factor for adult-onset disease (Ma et al. 2013). This has very important implications for the future health of Western nations where the rates of obesity are increasing dramatically. A major challenge is determining if the development of disease is due to a prenatal exposure occurring at a particular time in gestation. Epidemiological studies of offspring conceived/born during the Dutch winter famine suggested that those born to mothers exposed to the famine during the first trimester of pregnancy had increased rates of obesity, altered lipid profiles, and cardiovascular disease. By contrast, those exposed in mid-gestation were more likely to develop renal dysfunction whilst exposure to the famine during late gestation often caused a low birth weight (Schulz 2010). Recent studies have shown that relatively short periods of fasting, such as for Ramadan, can cause alterations in maternal body composition and placental weight which were dependent upon the stage of pregnancy (Alwasel et al. 2011).
Animal models enable researchers to invoke a maternal perturbation at specific times of gestation to determine times of developmental sensitivity. Protein restriction throughout pregnancy in the rat results in offspring that are born small, develop high blood pressure (Woods et al. 2001), impaired renal function (Alwasel et al. 2012), glucose intolerance (Ozanne et al. 1996), and impaired fertility (Zambrano et al. 2005), suggesting that sustained nutritional deficits throughout pregnancy can elicit a wide variety of long-term abnormalities (Woods et al. 2001, 2005). Short-term infusions of glucocorticoids during early- or midgestation culminate in hypertension in both sheep (Dodic et al. 2002) and rat offspring respectively (Ortiz et al. 2003, Singh et al. 2007a). Interestingly, the outcome is highly dependent upon the timing of exposure as the same level of glucocorticoid exposure did not result in hypertension when administered at other stages of development (Dodic et al. 1999, Ortiz et al. 2003). Models of uteroplacental insufficiency have been developed to explore the long-term effects of reduced placental function in late gestation in the rat, which coincides with the period of rapid fetal growth. This procedure results in fetal growth restriction and male offspring develop elevated blood pressure (Wlodek et al. 2005, 2007), impaired glucose tolerance (Siebel et al. 2008), and vascular dysfunction (Tare et al. 2012). Collectively, these studies suggest that adult-onset disease may follow either an acute or a chronic prenatal insult but outcomes may depend upon the timing of exposure. As discussed below, these differential outcomes may in part relate to the stage of kidney development, suggesting that it is the relative developmental stage of organs that is important rather than the gestational age per se.

\section{Renal development is susceptible to prenatal challenges}

Although many of the animal studies described above vary in the timing, duration, type, and severity of the insult to the developing fetus, a strong common finding across most of these models has been impairments in renal development (Table 1; Moritz et al. 2008). This has led to speculation that impaired renal development may be a common factor contributing to the programing of disease. During development, three distinct urinary excretory organs are formed: the first two, the pronephros and mesonephros are temporary organs that precede the formation of the permanent kidney, the metanephros. The metanephros commences growth around day 30 in the human when the ureteric bud buds off the Wolffian duct and invades the surrounding metanephric mesenchyme. Through branching morphogenesis, the ureteric tree is formed, completing the scaffold for the future nephrons. Molecular signals from 


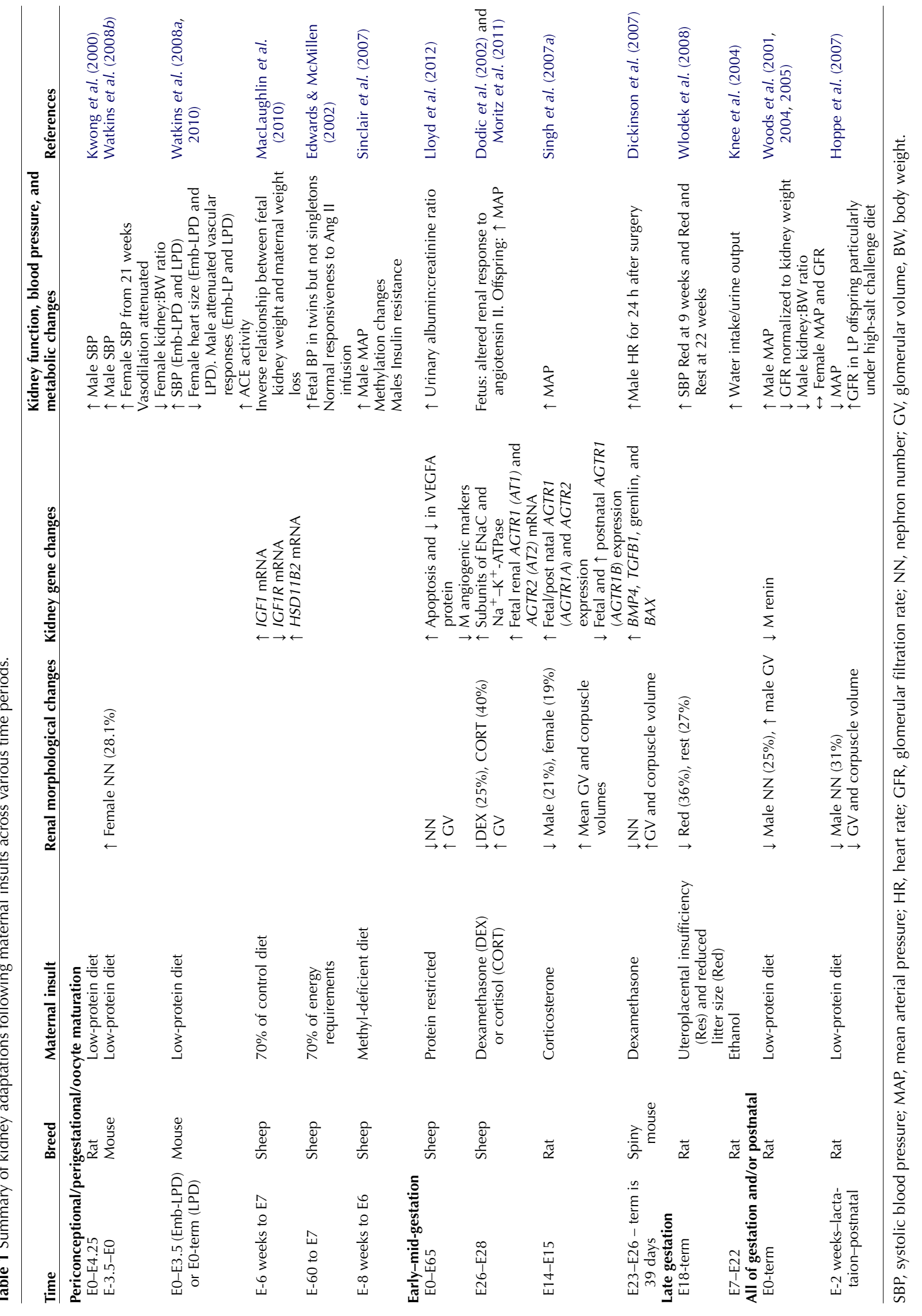


the ureteric tree cause cells of the metanephric mesenchyme to condense and form the complex nephron structure (Moritz et al. 2008). This process of nephrogenesis in the permanent metanephric kidney is complete by $\sim 36$ weeks in the human and, therefore, although a growth-restricted infant may experience 'catch-up' growth postnatally, the kidney cannot form any more nephrons. It is imperative to note that the timing of renal development differs amongst species with rats and mice not commencing development of the metanephric kidney until mid-gestation and nephrogenesis continuing for some days after birth (Singh et al. 2012). This may be taken into consideration when interpreting the findings from animal studies.

\section{Effects on nephron number}

A human kidney contains on average $\sim 1$ million nephrons, but the range in a normal human population varies considerably (Hughson et al. 2006). Nephron number is most accurately determined by counting glomeruli using unbiased stereological methods that at the current time can only be done on kidneys obtained at autopsy. Although this makes it difficult to assess nephron endowment routinely in humans, studies have demonstrated that growth-restricted infants have small kidneys with fewer nephrons (Hinchliffe et al. 1992). There is a strong association between birth weight and nephron number with $\sim 300000$ more nephrons for every kilogram increase in birth weight (Hughson et al. 2006). This suggests in human babies that any suboptimal in utero environment that slows fetal growth may result in a congenital nephron deficit. Nephron endowment has been explored in the animal models of programing described above and as shown in the table, results in a nephron deficit of up to $30-40 \%$. Consistent with a reduction in nephron endowment, animal studies have demonstrated alterations in molecular pathways that regulate renal development. Insults such as dexamethasone (Dickinson et al. 2007, Singh et al. 2007 b) or alcohol exposure (Gray et al. 2010) alter mRNA expression levels of factors controlling branching morphogenesis, thereby suggesting inhibition of ureteric branching in the developing kidney.

\section{How does a low nephron number contribute to disease?}

A low nephron number has been most strongly associated with a risk for increased blood pressure. Brenner et al. (1988) proposed some years ago that hypertension was directly related to glomerular number and this was demonstrated in a carefully controlled study where individuals with clinically diagnosed hypertension had approximately half the number of nephrons compared with a control population (Keller et al. 2003). The 'Brenner hypothesis' suggests that a congenital nephron deficit results in an inability to maintain normal fluid and electrolyte balance (particularly sodium) resulting in volume expansion, glomerular hyperfiltration, and systemic hypertension (see Fig. 1). Animal models have tested aspects of this hypothesis. Lategestation ovine fetuses and young lambs demonstrate augmented expression of renal sodium channels following early-gestation maternal glucocorticoid exposure (Moritz et al. 2011). Moreover, increased renal protein levels of the bumetanide-sensitive $\mathrm{Na}-\mathrm{K}-2 \mathrm{Cl}$ cotransporter (SLC12A1 (BSC1)) and the thiazide-sensitive $\mathrm{Na}-\mathrm{Cl}$ cotransporter (SLC12A3 (TSC)) have been observed in offpsring following maternal low-protein diet throughout pregnancy (Manning et al.

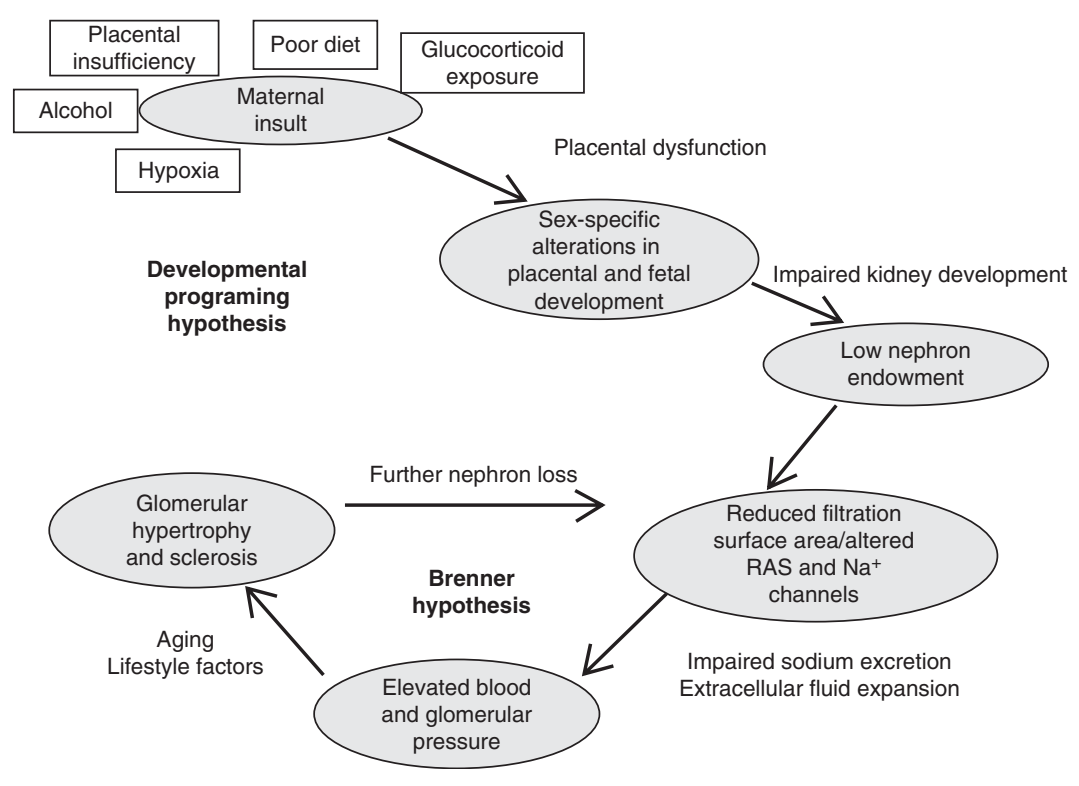

Reproduction (2014) 147 R189-R198
Figure $1 \mathrm{~A}$ schematic representation depicting a pathway through which a multitude of prenatal perturbations may result in hypertension. The original Brenner hypothesis, suggesting a congenital nephron deficit predisposes to hypertension, has been adapted to include postnatal factors which may modify disease progression including aging and lifestyle factors. 
2002). This is speculated to result in increased sodium retention and volume expansion and be a contributing factor to adult-onset hypertension. The renin-angiotensin system (RAS) is also implicated in some of these programing outcomes. Specifically, the RAS is often suppressed during renal development, potentially contributing to the nephron deficit, followed by a compensatory increase in activity in postnatal life (Moritz et al. 2010). Given the integral role of the RAS in fluid balance and blood pressure control in the adult, long-term upregulation of this system, combined with the low nephron endowment, provides a highly plausible pathway through which prenatal insults may result in hypertension. The reasons for this high susceptibility of the developing kidney to insult are not known but are likely related to the way the kidney functions in utero. Although the fetal kidney is functional and produces urine (Moritz et al. 2008), which is essential for amniotic fluid production, fetuses with renal agenesis can grow to term. This is because, during development, much of the fetal fluid and electrolyte balance is controlled by the placenta. It has been suggested that when challenged by nutrient availability, the growing fetus preferentially maintains supply to the brain and heart at the expense of organs such as the kidney (Barker et al. 2012).

It should be noted that a nephron deficit in isolation does not always result in disease outcomes, suggesting that other factors may contribute to disease susceptibility. Indeed, many children born with one kidney (unilateral renal agenesis), or have one removed in early life (thereby removing half the nephrons), do not develop overt hypertension (for review, see Lankadeva et al. (2014)). Increases in blood pressure can also be dissociated from nephron deficits in some animal models of glucocorticoid exposure (Ortiz et al. 2003) and in spontaneously hypertensive rats (Black et al. 2004). Whilst the prenatal perturbation increases the risk of dysfunction, disease does not occur in all individuals and outcomes are dependent upon factors such as the sex of the offspring (males in general being more susceptible than females) (Woods et al. 2001, 2005), age (elevated blood pressure may only develop with age), and postnatal lifestyle. The inclusion of a secondary insult or 'second hit' to exacerbate an underlying phenotype is commonly used in the field as a way to mimic postnatal lifestyle factors in a human population that may exacerbate underlying predispositions. For example, following uteroplacental insufficiency in rats, female offspring do not develop overt signs of dysfunction, however, with aging or during pregnancy (Gallo et al. 2012), renal and metabolic dysfunctions are unmasked. Similarly, offspring from dams exposed to protein restriction, during pregnancy were more vulnerable to secondary renal insult from advanced glycation products (Zimanyi et al. 2006).

\section{Critical periods for renal development}

A maternal low-protein diet administered throughout pregnancy resulted in offspring with reduced nephron endowment and hypertension. This was also observed when the dietary restriction was imposed during the second (but not first) half of gestation, corresponding to the period of nephrogenesis (Woods et al. 2004). Shortterm glucocorticoid exposure in different species (sheep, rat, mouse, and spiny mouse) has demonstrated that maternal exposure specifically during early kidney development can consistently reduce nephron number although the relative period of gestation is remarkably different. In each species, glucocorticoid was administered for 2-3 days during a time when the metanephric kidney was in the very early stages of development. In the sheep, this was relatively early in pregnancy (days 26-28 where term is 150 days, Dodic et al. (2002)), when compared with the rat (day 14/15 out of a 22-day pregnancy, Singh et al. (2007a)), the mouse (days 12-14 of a 19-day gestation, O'Sullivan et al. (2013)), and the Spiny mouse (the exposure was mid-gestation: days 2123 of a 39-day pregnancy, Dickinson et al. (2007)). These findings suggest that early impairment of renal development cannot be restored later in gestation, even if the insult is removed. Late renal development is also a period of susceptibility as nephron number is increasing exponentially at this time. Uteroplacental insufficiency induced in late pregnancy or a modest reduction in litter size at birth (which causes maternal stress and altered lactation) can both decrease nephron endowment in the rat (Wlodek et al. 2007, 2008). This presumably affects the final few branching events of the ureteric tree. In contrast to an insult in early development, nephron endowment could be restored following a late-gestation perturbation. Cross-fostering offspring from a dam that underwent uteroplacental insufficiency onto a control dam resulted in almost complete restoration of nephron endowment and prevention of hypertension in adult life (Wlodek et al. 2007).

Exceptions to the finding of a reduced nephron endowment have been observed when an insult was administered in the early postnatal period. Overnutrition during lactation (due to severe litter reduction) was shown to increase nephron number in rats (Boubred et al. 2007). Despite the increased nephron number, this insult resulted in offspring with elevated blood pressure. Similarly, a maternal low-protein diet specifically during oocyte maturation in mice ( -3.5 days until mating) resulted in female offspring with smaller kidneys relative to body weight but paradoxically an increased nephron number (Watkins et al. 2008b). To our knowledge, this is the only study to assess nephron endowment following a periconceptional exposure, and further investigation is required. These findings suggest that insults at this very early time point of development may program disease by different mechanisms to gestational exposures. 
Alternately, it may be that the additional nephrons formed do not function entirely normally and the increase in nephron endowment in fact represents dysregulated renal development. This raises many important questions as to whether insults around the time of conception can also program adult-onset disease. The second part of this review will focus on this question.

\section{Human periconceptional exposures}

The period immediately before and following conception potentially represents a period of exposure to a range of perturbations some of which may be modified upon recognition of pregnancy. For example, 22.5\% of women report an episode of drinking during the first month of gestation but not later in pregnancy (Ethen et al. 2009), whilst many women alter their diet or begin taking dietary supplements when knowingly pregnant (Elmadfa \& Meyer 2012). Studies into long-term health of babies from assisted reproductive technologies have shown that children born following IVF have higher systolic and diastolic blood pressure, as well as higher fasting blood glucose levels (Ceelen et al. 2008). This suggests that manipulation of the embryo around the time of conception can alter development and can have long-lasting effects.

\section{Animal models of periconceptional exposure}

The only perturbation studied to any large extent during the periconceptional period is altered maternal nutrition with a limited number of studies in other relevant models such as ethanol exposure and methyl-deficient diets. The data are primarily derived from either rodent (see Watkins et al. (2008a,b, 2010)) or sheep models (Edwards \& McMillen (2002), MacLaughlin et al. 2007, 2010, Todd et al. 2009, Lie et al. 2013, Nicholas et al. 2013). As shown in the Table 1, the timing of the periconceptional insult may include oocyte maturation and the preimplantation period.

\section{Rodent models}

The periconceptional model utilizing maternal lowprotein diets in the rodent allows separation of periconceptional and preimplantation influences by breaking the period of exposure down into key time points including oocyte maturation (Egg-LPD) or embryonic development (Emb-LPD). These short-term periods of nutrient restriction have been compared with a low-protein or control diet throughout pregnancy. Following a low-protein diet around conception, maternal control of insulin and glucose was impaired in association with changes in amino acid levels in both the maternal and blastocyst environment. Furthermore, changes in trophectoderm, inner cell mass, and total cell numbers were observed (Kwong et al. 2000, Watkins et al. 2008a,b, Eckert et al. 2012). These changes in the maternal milieu highlight the importance of understanding the environment around the time of conception.

Offspring phenotypes have been explored following periconceptional challenges. Reductions in heart and kidney weights relative to body weight were shown, though tended to be sexually dimorphic (Kwong et al. 2000, Watkins et al. 2008a,b). Increases in systolic blood pressure were demonstrated following a period of protein restriction through either the period of oocyte maturation ( -3.5 until mating) or the preimplantation (0-3.5/4.5 days of gestation) period in both the mouse and rat (Kwong et al. 2000, Watkins et al. 2008a,b). As shown in the Table 1, these outcomes are similar to those following a low-protein diet throughout pregnancy (Woods et al. 2004). Preimplantation low-protein diet exposure also caused attenuated vascular responsiveness and changes in the RAS activity (Watkins et al. 2010).

\section{Sheep models}

Using a maternal diet containing $70 \%$ of required energy from 6 weeks before mating until day 7 of pregnancy, late gestation twin fetuses had increased blood pressure (Edwards \& McMillen 2002). Kidneys of undernourished fetuses were of a similar weight to control at day 50 of pregnancy, though they exhibited increased expression of renal IGF1 and HSD11B2 mRNA but decreased IGF1R mRNA expression (MacLaughlin \& McMillen 2007, MacLaughlin et al. 2010), suggesting that renal development may be affected. In late gestation, fetuses of ewes that were undernourished around conception had elevated insulin concentrations and altered abundance of factors regulating adipogenesis and lipogenesis in the perirenal fat. Undernutrition during the preimplantation period decreased the abundance of phosphorylated mTOR, which was increased following periconceptional undernutrition in ewes carrying twins (Lie et al. 2013). These studies highlight that changes in visceral and brown fat, evident during fetal life, may contribute to the development of insulin resistance in adulthood, which has been found in adult sheep offspring following periconceptional undernutrition (Todd et al. 2009).

Altered maternal nutrition around conception in obese mothers is now being explored, which is of clinical relevance as obese women are advised to lose weight to improve the chances of becoming pregnant. Overnutrition to induce obesity was followed by a period of restricted nutrition around conception in an ovine model. All embryos were then transferred into control ewes for the remainder of pregnancy. Increased total fat was found in female offspring at 4 months of age following an environment of overnutrition without restriction, whilst this effect was ameliorated by a period 
of restriction (Rattanatray et al. 2010). An increased responsiveness to stress was shown in female lambs, as well as changes in methylation patterns following a period of restriction during the periconceptional period (Zhang et al. 2010). Altered nutrition around conception resulted in epigenetic changes in the insulin signaling pathway, involving hepatic micro RNAs. Hepatic MIR29B (miR-29b), MIR107 (miR-107), and MIR103 (miR-103) were upregulated in overweight ewes, though following restriction, only the change in MIR103 (miR-103) persisted (Nicholas et al. 2013).

Other clinically relevant perturbations include periconceptional alcohol exposure that resulted in changes in $\mathrm{E}$ - and $\mathrm{N}$-cadherin expression and slowed development of embryos (Coll et al. 2011). Periconceptional alcohol exposure has also been shown to impair placental development that may contribute to fetal growth restriction (Gardebjer et al. 2014). A methyl-deficient diet during this period of development has been shown to change immune function, glucose metabolism, cardiovascular function and methylation in sheep offspring (Sinclair et al. 2007). It is important to note that many of the studies to date have focused on embryonic/fetal outcomes and relatively young offspring. As highlighted above, the importance of studying aged or aging offspring is evident as many of the outcomes of the prenatal environment are not seen until later in life and are often only apparent after exposure to lifestyle influences.

\section{Potential mechanisms underlying developmental programing}

The emerging picture suggests that multiple gestational insults may alter growth trajectories and increase the chances of obesity, insulin resistance, and cardiovascular disease later in life through programed changes in the fetus, which include changes to nephron endowment. The question remains as to the underlying mechanisms through which this occurs. As already discussed, although the perturbations can be diverse, the outcomes are remarkably similar suggesting converging mechanisms to impact on key organ systems. Moreover, these programing events are clearly related to inappropriate nutrient supply and as recent data using models of periconceptional nutrient restriction have suggested, they may be determined before implantation. The preimplantation period represents a critical time of susceptibility, as this is a period in which the embryo undergoes a series of critical developmental events, which set up its future growth trajectory. These include zygotic genome activation (Zeng \& Schultz 2005) as well as morphological (Johnson 2009) and metabolic differentiative events with the outcome being blastocyst formation and the establishment of the two primary cell lineages, the inner cell mass and the cells of the trophectoderm. Nutrient availability impacts not only on the ability of the newly fertilized zygote to form a blastocyst but also on the number of cells that form the progenitor pool in the blastocyst. These are the progenitor cells of the embryo proper and the placental membranes respectively. Significantly, one of the early determinants of developmental potential and fetal size at birth is reported to be the number of cells specifically in the inner cell mass at day 4 (Kaye \& Gardner 1999, Kwong et al. 2000, Fleming et al. 2004). Whilst the molecular mechanisms involved in the regulation of embryonic cell number in response to nutrient perturbations are elusive, these may include mTor signaling (Eckert et al. 2012) as well as the hexosamine signaling pathways (Pantaleon et al. 2010).

Evidence also supports a role for epigenetic mechanisms underlying programing, affecting growth of numerous tissues to alter susceptibility to hypertension, and other adult-onset diseases. Studies in sheep show that clinically relevant reductions in folate and methionine around the time of conception lead to widespread changes in methylation (mostly hypomethylation), which lead to increased adiposity, insulin resistance, reduced immune function, and high blood pressure (Sinclair et al. 2007). The preimplantation period is a critical developmental checkpoint because it is one of the two points during development where epigenetic reprograming occurs, the other being in primordial germ cells at about the time of migration to the genital ridges (Seisenberger et al. 2013). This epigenetic reprograming involves the erasure of DNA methylation and repressive histone modifications (such as $\mathrm{H} 3 \mathrm{~K} 4$ ) and their resetting following de novo methylation after compaction (Reik 2007). This allows for cell fate plasticity and makes way for new generations to develop and grow into adults on the basis of their genetic make-up and their developmental environment. However, some epigenetic information does spill over into the next generation giving rise to transgenerational cellular memory (Lange \& Schneider 2010) of an adverse environment in the absence of the original environmental trigger. Interestingly, however, it is the epigenetic paternal inheritance that is erased (Reik 2007). Whilst it is not clear whether hypomethylation is the basis for all developmental programing phenomena, data from mice suggest that in vitro culture does indeed alter levels of critical modifiers of the epigenome such as the de novo DNA methyl transferase Dnmt3/ during this stage in development (Kafer et al. 2011) to potentially impact on de novo genome-wide methylation following resetting of epigenetic marks.

Although speculative, differential establishment of the methylation landscape in the placental progenitor pool (trophectoderm cells) may also underlie the sexually dimorphic nature of these perturbations, given that the endocrine placenta is poised to be a key mediating tissue in responding to a dynamic and changing maternal environment. Sex differences in how this tissue develops 
and therefore responds to the same maternal milieu are likely to contribute to the altered susceptibility of male and female fetuses to long-term programing outcomes. This may be related to expression of key imprinted growth factors such as IGF2 that may be differentially expressed in male versus female placentae or differences in placental structure as a result of differences in nutrient handling.

\section{Summary}

The programing of adult-onset disease, particularly hypertension, is strongly linked with impaired renal development. Experimental evidence suggests that the kidney is vulnerable following a range of maternal insults across gestation resulting in a congenital nephron deficit. Poor lifestyle choices and aging, in combination with the reduced nephron endowment, render an individual more susceptible to the development of disease. However, few studies have explored the renal and long-term health consequences of exposures occurring around the time of conception. Insults at this time can alter early nutrient supply to the blastocyst resulting in epigenetic changes in both the embryo and placenta. Future studies focusing on a range of periconceptional lifestyle factors will determine the long-term outcomes but, more importantly, provide insight into the mechanisms involved. This knowledge is essential to allow preventative strategies or potential interventions to be implemented.

\section{Declaration of interest}

The authors declare that there is no conflict of interest that could be perceived as prejudicing the impartiality of the review.

\section{Funding}

The authors are supported by grants from the National Health and Medical Research Council (NH and MRC; grant number 1046137) of Australia and the University of Queensland. E S Dorey is funded by an Australian Postgraduate Award and Karen Moritz by an NH and MRC Senior Research Fellowship.

\section{Acknowledgements}

The authors would like to thank Dr James Cuffe for critical appraisal of the manuscript.

\section{References}

Alwasel SH, Abotalib Z, Aljarallah JS, Osmond C, Alkharaz SM, Alhazza IM, Harrath A, Thornburg K \& Barker DJ 2011 Secular increase in placental weight in Saudi Arabia. Placenta 32 391-394. (doi:10.1016/ j.placenta.2011.02.007)
Alwasel SH, Barker DJ \& Ashton N 2012 Prenatal programming of renal salt wasting resets postnatal salt appetite, which drives food intake in the rat. Clinical Science 122 281-288. (doi:10.1042/CS20110266)

Barker DJ 2007 The origins of the developmental origins theory. Journal of Internal Medicine 261 412-417. (doi:10.1111/j.1365-2796. 2007.01809.x)

Barker DJ \& Osmond C 1986 Infant mortality, childhood nutrition, and ischaemic heart disease in England and Wales. Lancet $\mathbf{1}$ 1077-1081. (doi:10.1016/S0140-6736(86)91340-1)

Barker DJ \& Thornburg KL 2013 Placental programming of chronic diseases, cancer and lifespan: a review. Placenta 34 841-845. (doi:10. 1016/j.placenta.2013.07.063)

Barker DJ, Lampl M, Roseboom T \& Winder N 2012 Resource allocation in utero and health in later life. Placenta 33 (Suppl 2) e30-e34. (doi:10. 1016/j.placenta.2012.06.009)

Black MJ, Briscoe TA, Constantinou M, Kett MM \& Bertram JF 2004 Is there an association between level of adult blood pressure and nephron number or renal filtration surface area? Kidney International 65 582-588. (doi:10.1111/j.1523-1755.2004.00406.x)

Boubred F, Buffat C, Feuerstein JM, Daniel L, Tsimaratos M, Oliver C, Lelievre-Pegorier M \& Simeoni U 2007 Effects of early postnatal hypernutrition on nephron number and long-term renal function and structure in rats. American Journal of Physiology. Renal Physiology 293 F1944-F1949. (doi:10.1152/ajprenal.00141.2007)

Brenner BM, Garcia DL \& Anderson S 1988 Glomeruli and blood pressure: less of one, more of the other? American Journal of Hypertension 1 335-347. (doi:10.1093/ajh/1.4.335)

Ceelen $M$, van Weissenbruch MM, Vermeiden JPW, van Leeuwen FE \& de Waal H 2008 Cardiometabolic differences in children born after in vitro fertilization: follow-up study. Journal of Clinical Endocrinology and Metabolism 93 1682-1688. (doi:10.1210/jc.2007-2432)

Coll TA, Tito LP, Sobarzo CMA \& Cebral E 2011 Embryo developmental disruption during organogenesis produced by CF-1 murine periconceptional alcohol consumption. Birth Defects Research. Part B, Developmental and Reproductive Toxicology 92 560-574. (doi:10.1002/bdrb. 20329)

Dickinson H, Walker DW, Wintour EM \& Moritz K 2007 Maternal dexamethasone treatment at midgestation reduces nephron number and alters renal gene expression in the fetal spiny mouse. American Journal of Physiology. Regulatory, Integrative and Comparative Physiology 292 R453-R461. (doi:10.1152/ajpregu.00481.2006)

Dodic M, Peers A, Coghlan JP, May CN, Lumbers E, Yu ZY \& Wintour EM 1999 Altered cardiovascular haemodynamics and baroreceptor-heart rate reflex in adult sheep after prenatal exposure to dexamethasone. Clinical Science 97 103-109. (doi:10.1042/CS19980356)

Dodic M, Hantzis V, Duncan J, Rees S, Koukoulas I, Johnson K, Wintour EM \& Moritz K 2002 Programming effects of short prenatal exposure to cortisol. FASEB Journal 16 1017-1026. (doi:10.1096/fj.01-1045com)

Eckert J, Porter R, Watkins AJ, Burt E, Brooks S, Leese HJ, Humpherson PG, Cameron IT \& Fleming TP 2012 Metabolic induction and early responses of mouse blastocyst developmental programming following maternal low protein diet affecting life-long health. PLOS ONE 7 e52791. (doi:10.1371/journal.pone.0052791)

Edwards LJ \& McMillen IC 2002 Periconceptional nutrition programs development of the cardiovascular system in the fetal sheep. American Journal of Physiology. Regulatory, Integrative and Comparative Physiology 283 R669-R679.

Elmadfa I \& Meyer AL 2012 Vitamins for the first 1000 days: preparing for life. International Journal for Vitamin and Nutrition Research 82 342-347. (doi:10.1024/0300-9831/a000129)

Eriksson JG, Forsen T, Tuomilehto J, Winter PD, Osmond C \& Barker DJ 1999 Catch-up growth in childhood and death from coronary heart disease: longitudinal study. BMJ 318 427-431. (doi:10.1136/bmj.318. 7181.427)

Ethen M, Ramadhani T, Scheuerle A, Canfield M, Wyszynski D, Druschel C, Romitti P \& S Natl Birth Defects Prevention 2009 Alcohol consumption by women before and during pregnancy. Maternal and Child Health Journal 13 274-285. (doi:10.1007/s10995-008-0328-2)

Fleming TP, Kwong WY, Porter R, Ursell E, Fesenko I, Wilkins A, Miller DJ, Watkins AJ \& Eckert JJ 2004 The embryo and its future. Biology of Reproduction 71 1046-1054. (doi:10.1095/biolreprod.104.030957) 
Gallo LA, Tran M, Moritz KM, Mazzuca MQ, Parry LJ, Westcott KT, Jefferies AJ, Cullen-McEwen LA \& Wlodek ME 2012 Cardio-renal and metabolic adaptations during pregnancy in female rats born small: implications for maternal health and second generation fetal growth. Journal of Physiology 590 617-630. (doi:10.1113/jphysiol.2011. 219147)

Gallo LA, Tran M, Moritz KM \& Wlodek ME 2013 Developmental programming: variations in early growth and adult disease. Clinical and Experimental Pharmacology \& Physiology 40 795-802. (doi:10.1111/ 1440-1681.12092)

Gardebjer EM, Cuffe JS, Pantaleon M, Wlodek ME \& Moritz KM 2014 Periconceptional alcohol consumption causes fetal growth restriction and increases glycogen accumulation in the late gestation rat placenta. Placenta 35 50-57. (doi:10.1016/j.placenta.2013.10.008)

Gluckman PD, Hanson MA, Cooper C \& Thornburg KL 2008 Effect of in utero and early-life conditions on adult health and disease. New England Journal of Medicine 359 61-73. (doi:10.1056/NEJMra 0708473)

Gray SP, Denton KM, Cullen-McEwen L, Bertram JF \& Moritz KM 2010 Prenatal exposure to alcohol reduces nephron number and raises blood pressure in progeny. Journal of the American Society of Nephrology 21 1891-1902. (doi:10.1681/ASN.2010040368)

Hales CN \& Ozanne SE 2003 For debate: fetal and early postnatal growth restriction lead to diabetes, the metabolic syndrome and renal failure. Diabetologia 46 1013-1019. (doi:10.1007/s00125-003-1131-7)

Hinchliffe SA, Lynch MR, Sargent PH, Howard CV \& Van Velzen D 1992 The effect of intrauterine growth retardation on the development of renal nephrons. British Journal of Obstetrics and Gynaecology 99 296-301. (doi:10.1111/j.1471-0528.1992.tb13726.x)

Hoppe CC, Evans RG, Moritz KM, Cullen-McEwen LA, Fitzgerald SM, Dowling J \& Bertram JF 2007 Combined prenatal and postnatal protein restriction influences adult kidney structure, function, and arterial pressure. American Journal of Physiology. Regulatory, Integrative and Comparative Physiology 292 R462-R469. (doi:10.1152/ajpregu. 00079.2006)

Hughson MD, Douglas-Denton R, Bertram JF \& Hoy WE 2006 Hypertension, glomerular number, and birth weight in African Americans and white subjects in the southeastern United States. Kidney International 69 671-678. (doi:10.1038/sj.ki.5000041)

Johnson MH 2009 From mouse egg to mouse embryo: polarities, axes, and tissues. Annual Review of Cell and Developmental Biology 25 483-512. (doi:10.1146/annurev.cellbio.042308.113348)

Kafer GR, Kaye PL, Pantaleon M, Moser RJ \& Lehnert SA 2011 In vitro manipulation of mammalian preimplantation embryos can alter transcript abundance of histone variants and associated factors. Cellular Reprogramming 13 391-401. (doi:10.1089/cell.2011.0011)

Kaye PL \& Gardner HG 1999 Preimplantation access to maternal insulin and albumin increases fetal growth rate in mice. Human Reproduction 14 3052-3059. (doi:10.1093/humrep/14.12.3052)

Keller G, Zimmer G, Mall G, Ritz E \& Amann K 2003 Nephron number in patients with primary hypertension. New England Journal of Medicine 348 101-108. (doi:10.1056/NEJMoa020549)

Knee DS, Sato AK, Uyehara CFT \& Claybaugh JR 2004 Prenatal exposure to ethanol causes partial diabetes insipidus in adult rats. American Journal of Physiology. Regulatory, Integrative and Comparative Physiology 287 R277-R283. (doi:10.1152/ajpregu.00223.2003)

Kwong WY, Wild AE, Roberts P, Willis AC \& Fleming TP 2000 Maternal undernutrition during the preimplantation period of rat development causes blastocyst abnormalities and programming of postnatal hypertension. Development 127 4195-4202.

Lange UC \& Schneider R 2010 What an epigenome remembers. Bioessays 32 659-668. (doi:10.1002/bies.201000030)

Lankadeva YR, Singh RR, Tare M, Moritz KM \& Denton KM 2014 Loss of a kidney during fetal life: long term consequences and lessons learnt. American Journal of Physiology. Renal Physiology.

Lie S, Morrison JL, Williams-Wyss O, Ozanne SE, Zhang S, Walker SK, Kleemann DO, MacLaughlin SM, Roberts CT \& McMillen IC 2013 Impact of embryo number and periconceptional undernutrition on factors regulating adipogenesis, lipogenesis, and metabolism in adipose tissue in the sheep fetus. American Journal of Physiology. Endocrinology and Metabolism 305 E931-E941. (doi:10.1152/ajpendo. 00180.2013)
Lloyd LJ, Foster T, Rhodes P, Rhind SM \& Gardner DS 2012 Protein-energy malnutrition during early gestation in sheep blunts fetal renal vascular and nephron development and compromises adult renal function. Journal of Physiology 590 377-393. (doi:10.1113/jphysiol.2011. 220186)

Luyckx VA, Bertram JF, Brenner BM, Fall C, Hoy WE, Ozanne SE \& Vikse BE 2013 Effect of fetal and child health on kidney development and longterm risk of hypertension and kidney disease. Lancet 382 273-283. (doi:10.1016/S0140-6736(13)60311-6)

Ma RC, Chan JC, Tam WH, Hanson MA \& Gluckman PD 2013 Gestational diabetes, maternal obesity, and the NCD burden. Clinical Obstetrics and Gynecology 56 633-641. (doi:10.1097/GRF.0b013e31829e5bb0)

MacLaughlin SM \& McMillen IC 2007 Impact of periconceptional undernutrition on the development of the hypothalamo-pituitaryadrenal axis: does the timing of parturition start at conception? Current Drug Targets 8 880-887. (doi:10.2174/138945007781386848)

MacLaughlin SM, Walker SK, Kleemann DO, Sibbons JP, Tosh DN, Gentili S, Coulter CL \& McMillen IC 2007 Impact of periconceptional undernutrition on adrenal growth and adrenal insulin-like growth factor and steroidogenic enzyme expression in the sheep fetus during early pregnancy. Endocrinology 148 1911-1920.

MacLaughlin SM, Walker SK, Kleemann DO, Tosh DN \& McMillen IC 2010 Periconceptional undernutrition and being a twin each alter kidney development in the sheep fetus during early gestation. American Journal of Physiology. Regulatory, Integrative and Comparative Physiology 298 R692-R699. (doi:10.1152/ajpregu.00495.2009)

Manning J, Beutler K, Knepper MA \& Vehaskari VM 2002 Upregulation of renal BSC1 and TSC in prenatally programmed hypertension. American Journal of Physiology. Renal Physiology 283 F202-F206.

McMillen IC \& Robinson JS 2005 Developmental origins of the metabolic syndrome: prediction, plasticity, and programming. Physiological Reviews 85 571-633. (doi:10.1152/physrev.00053.2003)

Moritz KM, Wintour EM, Black MJ, Bertram JF \& Caruana G 2008 Factors influencing mammalian kidney development: implications for health in adult life. Advances in Anatomy, Embryology, and Cell Biology 196 1-78.

Moritz KM, Singh RR, Probyn ME \& Denton KM 2009 Developmental programming of a reduced nephron endowment: more than just a baby's birth weight. American Journal of Physiology. Renal Physiology 296 F1-F9. (doi:10.1152/ajprenal.00049.2008)

Moritz KM, Cuffe JS, Wilson LB, Dickinson H, Wlodek ME, Simmons DG \& Denton KM 2010 Sex specific programming: a critical role for the renal renin-angiotensin system. Placenta 31 S40-S46. (doi:10.1016/ j.placenta.2010.01.006)

Moritz KM, De Matteo R, Dodic M, Jefferies AJ, Arena D, Wintour EM, Probyn ME, Bertram JF, Singh RR, Zanini S et al. 2011 Prenatal glucocorticoid exposure in the sheep alters renal development in utero: implications for adult renal function and blood pressure control. American Journal of Physiology. Regulatory, Integrative and Comparative Physiology 301 R500-R509. (doi:10.1152/ajpregu.00818.2010)

Naimi TS, Lipscomb LE, Brewer RD \& Gilbert BC 2003 Binge drinking in the preconception period and the risk of unintended pregnancy: implications for women and their children. Pediatrics 111 1136-1141.

Nicholas LM, Rattanatray L, Maclaughlin SM, Ozanne SE, Kleemann DO, Walker SK, Morrison JL, Zhang S, Muhlhausler BS, Martin-Gronert MS et al. 2013 Differential effects of maternal obesity and weight loss in the periconceptional period on the epigenetic regulation of hepatic insulin-signaling pathways in the offspring. FASEB Journal 27 3786-3796. (doi:10.1096/fj.13-227918)

Ortiz LA, Quan A, Zarzar F, Weinberg A \& Baum M 2003 Prenatal dexamethasone programs hypertension and renal injury in the rat. Hypertension 41 328-334. (doi:10.1161/01.HYP.0000049763.51269.51)

O'Sullivan L, Combes AN \& Moritz KM 2012 Epigenetics and developmental programming of adult onset diseases. Pediatric Nephrology 27 2175-2182. (doi:10.1007/s00467-012-2108-x)

O'Sullivan L, Cuffe JS, Paravicini TM, Campbell S, Dickinson H, Singh RR, Gezmish O, Black MJ \& Moritz KM 2013 Prenatal exposure to dexamethasone in the mouse alters cardiac growth patterns and increases pulse pressure in aged male offspring. PLOS ONE 8 e69149. (doi:10.1371/journal.pone.0069149)

Ozanne SE, Smith GD, Tikerpae J \& Hales CN 1996 Altered regulation of hepatic glucose output in the male offspring of protein-malnourished rat dams. American Journal of Physiology 270 E559-E564. 
Pantaleon M, Tan HY, Kafer GR \& Kaye PL 2010 Toxic effects of hyperglycemia are mediated by the hexosamine signaling pathway and $O$-linked glycosylation in early mouse embryos. Biology of Reproduction 82 751-758. (doi:10.1095/biolreprod.109.076661)

Rattanatray L, MacLaughlin SM, Kleemann DO, Walker SK, Muhlhausler BS \& McMillen IC 2010 Impact of maternal periconceptional overnutrition on fat mass and expression of adipogenic and lipogenic genes in visceral and subcutaneous fat depots in the postnatal lamb. Endocrinology 151 5195-5205. (doi:10.1210/en.2010-0501)

Reik W 2007 Stability and flexibility of epigenetic gene regulation in mammalian development. Nature 447 425-432. (doi:10.1038/ nature05918)

Schulz LC 2010 The Dutch Hunger Winter and the developmental origins of health and disease. PNAS 107 16757-16758. (doi:10.1073/pnas. 1012911107)

Seisenberger S, Peat JR \& Reik W 2013 Conceptual links between DNA methylation reprogramming in the early embryo and primordial germ cells. Current Opinion in Cell Biology 25 281-288. (doi:10.1016/j.ceb. 2013.02.013)

Siebel AL, Mibus A, De Blasio MJ, Westcott KT, Morris MJ, Prior L, Owens JA \& Wlodek ME 2008 Improved lactational nutrition and postnatal growth ameliorates impairment of glucose tolerance by uteroplacental insufficiency in male rat offspring. Endocrinology 149 3067-3076. (doi:10.1210/en.2008-0128)

Sinclair KD, Allegrucci C, Singh R, Gardner DS, Sebastian S, Bispham J, Thurston A, Huntley JF, Rees WD, Maloney CA et al. 2007 DNA methylation, insulin resistance, and blood pressure in offspring determined by maternal periconceptional B vitamin and methionine status. PNAS 104 19351-19356. (doi:10.1073/pnas.0707258104)

Singh RR, Cullen-McEwen LA, Kett MM, Boon WM, Dowling J, Bertram JF \& Moritz KM 2007a Prenatal corticosterone exposure results in altered AT1/AT2, nephron deficit and hypertension in the rat offspring. Journal of Physiology 579 503-513. (doi:10.1113/jphysiol.2006.125773)

Singh RR, Moritz KM, Bertram JF \& Cullen-McEwen LA 2007b Effects of dexamethasone exposure on rat metanephric development: in vitro and in vivo studies. American Journal of Physiology. Renal Physiology 293 F548-F554. (doi:10.1152/ajprenal.00156.2007)

Singh RR, Cuffe JS \& Moritz KM 2012 Short- and long-term effects of exposure to natural and synthetic glucocorticoids during development. Clinical and Experimental Pharmacology \& Physiology 39 979-989. (doi:10.1111/1440-1681.12009)

Tare M, Parkington HC, Bubb KJ \& Wlodek ME 2012 Uteroplacental insufficiency and lactational environment separately influence arterial stiffness and vascular function in adult male rats. Hypertension 60 378-386. (doi:10.1161/HYPERTENSIONAHA.112.190876)

Todd SE, Oliver MH, Jaquiery AL, Bloomfield FH \& Harding JE 2009 Periconceptional undernutrition of ewes impairs glucose tolerance in their adult offspring. Pediatric Research 65 409-413. (doi:10.1203/PDR. ob013e3181975efa)

Watkins AJ, Ursell E, Panton R, Papenbrock T, Ollis LH, Cunningham C, Wilkins A, Perry VH, Sheth B, Kwong WY et al. 2008a Adaptive responses by mouse early embryos to maternal diet protect fetal growth but predispose to adult onset disease. Biology of Reproduction $\mathbf{7 8}$ 299-306. (doi:10.1095/biolreprod.107.064220)

Watkins AJ, Wilkins A, Cunningham C, Perry VH, Seet MJ, Osmond C, Eckert JJ, Torrens C, Cagampang FRA, Cleal J et al. 2008b Low protein diet fed exclusively during mouse oocyte maturation leads to behavioural and cardiovascular abnormalities in offspring. Journal of Physiology $\mathbf{5 8 6}$ 2231-2244. (doi:10.1113/jphysiol.2007.149229)
Watkins AJ, Lucas ES, Torrens C, Cleal JK, Green L, Osmond C, Eckert JJ, Gray WP, Hanson MA \& Fleming TP 2010 Maternal low-protein diet during mouse pre-implantation development induces vascular dysfunction and altered renin-angiotensin-system homeostasis in the offspring. British Journal of Nutrition 103 1762-1770. (doi:10.1017/ S0007114509993783)

Wlodek ME, Westcott KT, O'Dowd R, Serruto A, Wassef L, Moritz KM \& Moseley JM 2005 Uteroplacental restriction in the rat impairs fetal growth in association with alterations in placental growth factors including PTHrP. American Journal of Physiology. Regulatory, Integrative and Comparative Physiology 288 R1620-R1627. (doi:10.1152/ajpregu. 00789.2004)

Wlodek ME, Mibus A, Tan A, Siebel AL, Owens JA \& Moritz KM 2007 Normal lactational environment restores nephron endowment and prevents hypertension after placental restriction in the rat. Journal of the American Society of Nephrology 18 1688-1696. (doi:10.1681/ASN. 2007010015)

Wlodek ME, Westcott K, Siebel AL, Owens JA \& Moritz KM 2008 Growth restriction before or after birth reduces nephron number and increases blood pressure in male rats. Kidney International 74 187-195. (doi:10. 1038/ki.2008.153)

Woods LL, Ingelfinger JR, Nyengaard JR \& Rasch R 2001 Maternal protein restriction suppresses the newborn renin-angiotensin system and programs adult hypertension in rats. Pediatric Research 49 460-467. (doi:10.1203/00006450-200104000-00005)

Woods LL, Weeks DA \& Rasch R 2004 Programming of adult blood pressure by maternal protein restriction: role of nephrogenesis. Kidney International 65 1339-1348. (doi:10.1111/j.1523-1755.2004. 00511.x)

Woods LL, Ingelfinger JR \& Rasch R 2005 Modest maternal protein restriction fails to program adult hypertension in female rats. American Journal of Physiology. Regulatory, Integrative and Comparative Physiology 289 R1131-R1136. (doi:10.1152/ajpregu.00037.2003)

Zambrano E, Rodriguez-Gonzalez GL, Guzman C, Garcia-Becerra R, Boeck L, Diaz L, Menjivar M, Larrea F \& Nathanielsz PW 2005 A maternal low protein diet during pregnancy and lactation in the rat impairs male reproductive development. Journal of Physiology $\mathbf{5 6 3}$ 275-284. (doi:10.1113/jphysiol.2004.078543)

Zeng F \& Schultz RM 2005 RNA transcript profiling during zygotic gene activation in the preimplantation mouse embryo. Developmental Biology 283 40-57. (doi:10.1016/j.ydbio.2005.03.038)

Zhang S, Rattanatray L, MacLaughlin SM, Cropley JE, Suter CM, Molloy L, Kleemann D, Walker SK, Muhlhausler BS, Morrison JL et al. 2010 Periconceptional undernutrition in normal and overweight ewes leads to increased adrenal growth and epigenetic changes in adrenal IGF2/H19 gene in offspring. FASEB Journal 24 2772-2782. (doi:10.1096/fj.09154294)

Zimanyi MA, Denton KM, Forbes JM, Thallas-Bonke V, Thomas MC, Poon F \& Black MJ 2006 A developmental nephron deficit in rats is associated with increased susceptibility to a secondary renal injury due to advanced glycation end-products. Diabetologia 49 801-810. (doi:10.1007/ s00125-006-0175-x)

Received 25 September 2013

First decision 4 November 2013

Revised manuscript received 25 March 2014

Accepted 31 March 2014 